\title{
Development of Spring Loaded Abrasive Float Polishing Machine Setup (SLAFP)
}

\author{
Asmita A Pardeshi* andV S Kanthale \\ Mechanical Department, MIT College of Engineering, Savitribai Phule University Pune, Pune, India
}

Accepted 02 March 2016, Available online 15 March 2016, Special Issue-4 (March 2016)

\begin{abstract}
Spring Loaded Abrasive Float Polishing is the method of polishing a work piece surface by using a sharp edged thin metallic material brush with alumina abrasives. It is a process by which material is precisely removed from a work piece to produce a desired dimension, surface finish, or shape. Surface finishes in the nanometer range can also be produced using this technique, which makes it an attractive method for materials processing. The process is different than conventional methods of polishing due to the fact that abrasives are much finer and the process is controlled efficiently. The machine will be applicable for nano level surface finish application as required in industries. The machine has the advantages as less cost, versatility, high accuracy and precision. The apparatus is designed for polishing number of work pieces simultaneously with high surface accuracy. The spindle was made according to dimensions of chamber. A fixture was made for resisting shocks and supporting the apparatus during polishing and springs are used for observing shocks and vibrations.
\end{abstract}

Keywords: Polishing, Metallic, Abrasives, Surface Finish, Nano- finishing, surface accuracy.

\section{Introduction}

Final finishing operations in manufacturing of precise parts are always of concern owing to their most critical, labor intensive and least controllable nature. In the era of nanotechnology, deterministic high precision finishing methods are of utmost importance and are the need of present manufacturing scenario. The need for high precision in manufacturing was felt by manufacturers worldwide to improve interchange ability of components, improve quality control and longer wear/fatigue life.

Taniguchi reviewed the historical progress of achievable machining accuracy during the last century. $\mathrm{He}$ had also extrapolated the probable further developments in micro technology and nanotechnology; the machining processes were classifieds into three categories on the basis of achievable accuracy viz. Conventional machining, precision machining and ultra-precision machining. Ultra precision machining are the processes by which the highest possible dimensional accuracy is, or has been achieved at a given point of time. This is a relative definition which varies with time. It has been predicted that by $2000 \mathrm{AD}$, machining accuracies in conventional processes would reach $1 \mu \mathrm{m}$, while in precision and ultra-precision machining would reach $0.01 \mu \mathrm{m}$ (10

*Corresponding author: Asmita A Pardeshi $\mathrm{nm})$ and $0.001 \mu \mathrm{m}(1 \mathrm{~nm})$ respectively. His predictions made around two decades before are in line with the current advances in manufacturing technology. These accuracy targets for today's ultra-precision machining can't be achieved by simple extension of conventional machining processes and techniques.

Polishing is the removal of material to produce a scratch-free, specular surface using fine $(<3 \mu \mathrm{m})$ abrasive particles. Polishing is typically done at very low speeds using either polishing cloths, abrasive films, or specially designed lapping plates. Chem-mechanical polishing (CMP) is a technique that combines both chemical and mechanical polishing principles to achieve uniform removal rates of a highly composite specimen (such as integrated circuit device fabrication). CMP is typically done using a hard polyurethane polishing pad combined with slurry of finely dispersed alumina or silica particles in an alkaline solution.

\section{Spring Loaded Abrasive Float Polishing Setup}

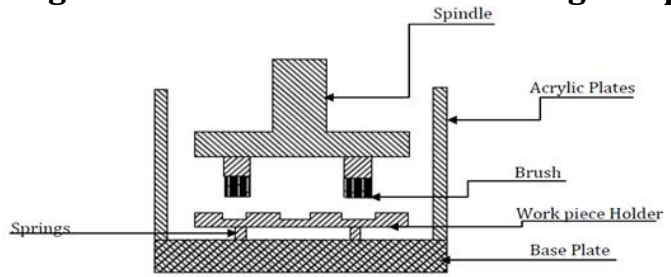

Fig.1 Schematic diagram of Spring Loaded Abrasive Float Polishing setup 
Constructional feature of Spring Loaded Abrasive Float Polishing consist of mainly the base plate, work piece holder, springs, brush, spindle, abrasive slurry in its construction. The materials used for various parts if the setup is given in Table1The various functions of the parts of the setup can be given as follows:

Table 1: Materials used for Spring Loaded Abrasive Float Polishing Machine

\begin{tabular}{|c|c|c|}
\hline S.No & Part & Material \\
\hline 1. & Base Plate & Mild Steel \\
\hline 2. & Acrylic Plate & Transparent Glass \\
\hline 3. & Work Piece Holder & Stainless Steel \\
\hline 4. & Springs & Stainless-Steel Wire \\
\hline 5. & Brush & Thin Brass Wire \\
\hline 6. & Spindle & Stainless Steel \\
\hline 7. & Abrasive Slurry & Abrasive Grains \\
\hline
\end{tabular}

\subsection{Base Plate}

Base plate is used to provide support to whole apparatus as well as damp vibrations.

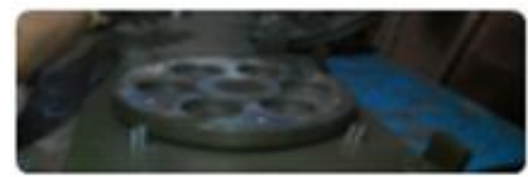

Fig.2 Base Plate

\subsection{Acrylic Plate}

Acrylic Plates give protection to the worker and to provide transparent viewing as well it enhances the aesthetics and ergonomic considerations.

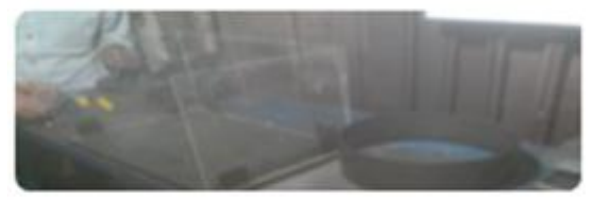

Fig .3 Acrylic plates

\subsection{Work piece holder}

To hold, locate and clamp the work piece. The work piece is perfectly located in the work piece holder. It is provided with no free play and avoids the movements of the work piece in any of the directions.

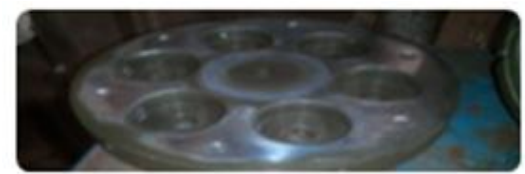

Fig.4 Workpiece Holder

\subsection{Spring}

The function of the spring is to cushion, absorb or control energy due to either shock or vibration, to control motion by maintaining contact and to apply forces, as in brakes.

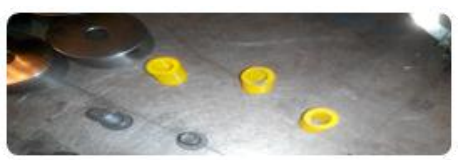

Fig.5Springs

\subsection{Brush}

This is the most important part which is used for the polishing of the work piece. It is very thin type of brush and it efficiently removes a very small amount of material from the work piece to give a very high grade surface finish.

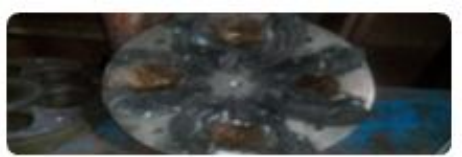

Fig.6 Brush

\subsection{Abrasive Slurry}

Aluminum oxide is best for polishing germanium and ceramics but it wears fast. Boron carbide is most expensive material but suitable for polishing tungsten carbides. Silicon carbide is difficult to keep in suspension. Diamond and rubies are nicely polished using diamond powder which gives good surface finish. The size of abrasive varies between 200 to 2000 grit. Coarse grade are used for roughing and finer grads are used for the finishing.

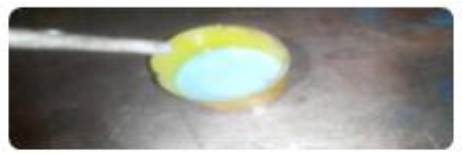

Fig.7 Abrasive Slurry

Spindle: Spindle is used to give rotary motion to the brushes and is coupled to the motor.

\subsection{Principle}

The fundamental principle of this process involves the use of a brush (Thin wire brass metal) with abrasives (Aluminum oxide). The brush is feed against the work piece and is rotted with a high speed.

The material removal occurs due to the erosion caused by the abrasive particles and brushes, 
impacting on the surface with high speed. With repeated impact of abrasives and brush, small bits of material gets loosened and a fresh surface is exposed.

\subsection{Working of Spring Loaded Abrasive Float Polishing}

At first the work pieces are properly clamped at their positions, the process uses a brush and abrasive slurry for polishing work piece. The brush is fed against the work piece. The base plate and the work piece holder are fixed and do not move. As the brush comes in contact with the work piece, the spindle is rotated which results in the rotation of the brush. The brush continuously rubes against the surface of work piece. Due to continue rotation of the spindle, a small amount of material is removal from the work piece. The new surface is exposed to the brush. The movement of brush can be precisely controlled which results in the efficient process control. When the process is continued for some time, the work piece gets polished with very high accuracy and surface finish. The process is able to polish and size work piece, if we want to polish a work piece of specific shape, we can simply change the work piece holder having the shape of work piece.

\subsection{Process Parameters}

Brush closeness: The brush should remain much closed with the work piece initially for a rouging period. To obtain a very high surface finish, the optimum contacts with the work piece from the brush should be used.

\subsection{Speed of rotation of brush:}

The speed of rotation of brush should be high to have the required accuracy, surface finish and to avoid chatter marks. If the speed is slow, then there wear and tear will takes place which will result in scratches on the work piece.

\subsection{Abrasive slurry}

Aluminum oxide is best for polishing germanium and ceramics but it wears fast. Boron carbide is most expensive material but suitable for polishing tungsten carbides. Silicon carbide is difficult to keep in suspension. Diamond and rubies are nicely polished using diamond powder which gives good surface finish. The size of abrasive varies between 200 to 2000 grit. Coarse grade are used for roughing and finer grads are used for the finishing.

\section{Results and Discussion}

Figure illustrates the component that was tested and the results found. The Fig.a shows the component before machining using Spring Loaded Abrasive Float Polishing Setup whereas the Fig.2 shows the component after the machining operation done.

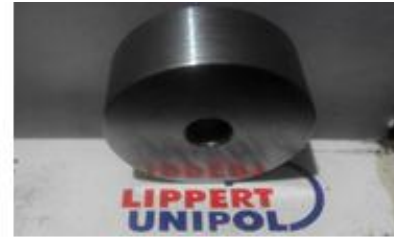

Fig .a

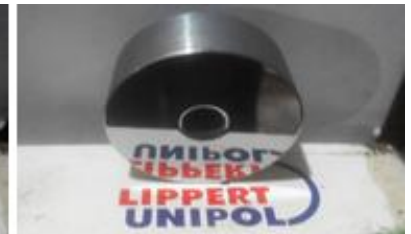

Fig .b
Fig a- Component before polishing Fig b-Component after polishing

In the experimental procedure followed of the spring loaded abrasive float polishing setup, there is no thermal distortion to the work piece material, as there is less heat is generated. Also, the process is very easy to carry out hence less operator skill is required. Considering the time required for machining the time for polishing is less than other processes conventional processes used therefore it save's a lot of time compared to other processes. Also the work piece is precisely located and has very less locating, clamping and unclamping time, this also serves a major factor contributed to the time saving with the Spring Loaded Abrasive Float Polishing Setup.

During machining the brush is continuously rotated with the help of the spindle which is mounted on the machine, due to this constantly moving of brush, the brush has negligible wear. The machine can operate for long period of time and the life of brush is good. Here very smooth work piece surface is obtained and very precise control of dimensions of the work pieces are also obtained. The properties of machined polished work pieces or magnetic materials are not affected by Spring Loaded Abrasive Float Polishing machine. Even during this process no burrs produced. As the production in done in batches high production rate is obtained also the process has flexibility for the size of the work piece. More productivity than conventional methods is obtained due to various factors involved such as time and the batch production system involved. Here the material does not go any metallurgical changes and is free from surface cracks therefore more quality and accuracy is obtained.

No need of cooling medium, as there is less heat is generated in the machining process due to various factors considered above major being the time involved. The cost of the apparatus, maintenance cost, and the running cost of Spring Loaded Abrasive Float Polishing setup is very less as compared to other processes.

\section{Various applications}

The various application of spring loaded abrasive float polishing can be applied to the following's field which include Cam, Jigs, Gauges, Templates, Piston, Valve seats and Hydraulic valve spool 


\section{Conclusions}

The various conclusions drown can be given as follows:

1. On the basis of work done during the preparation of the project, it is found that a very fine control of dimensions of the work piece can be obtained.

2. No other processes can achieve a high grade of surface finish at its price range than that of the Spring Loaded Abrasive Float Polishing process.

3. The setup is affordable at low cost which is beneficial to any manufacturing industry.

4. Surface finish in the nano range can be achieved using this technique, which makes it an attractive method for materials processing.

\section{Future Scope}

\section{Work holder}

The work holder used for this SLAFP machine is fixed for the work piece on which we performed different experiments. In real situations different size and shapes of work pieces are to be polished. For this purpose we can use a flexible work holder. We can clamp work pieces of different shapes and size with the help of flexible work holder.

\section{Abrasive slurry}

The abrasive slurry used in the process of spring loaded abrasive float polishing is aluminum oxide. By using silicon nitride or boron carbide finer abrasive slurries we can achieve still more finishing.

\section{Automation}

Automation or automatic control is the use of various control systems for operating equipment such as machinery, processes. The biggest benefit of automation is that it saves labor.

\section{Dust remover}

In SLAFP process, dust is collected at the bottom of the base plate. To remove that dust a considerable time is involved. By using a dust remover, we can remove that dust quickly and effectively. To achieve this Dust collector will be introduced in machine to collect that fine material (Burr) removed from the work pieces as well as the used abrasives.

\section{References}

V K Jain, Nano Finishing Techniques

Taniguchi, N. Current status in, and future trends of ultraprecision machining and ultrafine material processing, Annals of CIRP, vol. 32/2, 1983, pp 573-582

Lapping and polishing basics Southbay Technology.inc

Amir Torkman, (1998), design and fabrication of high precion wafer polishing machine.

Don Easrburn, Abrasive Technical Information.

Brushresearch, British Research Manufacturing co.inc

Béla Leffler ,Stainless Steels and Their Properties.

Siegfried Heckl,(2008),Abrasives, essential components of polishing Hoffmann Minera 